\title{
Lutas políticas, disposições e transações sociais em microcampos bancários
}

Political struggles, dispositions and social transactions in bank micro fields

Trabalhadores e clientes reconstituem nos espaços de trabalho bancários escolhas e posturas adequadas a cada situação experienciada, interagindo cotidiana e sistematicamente e participando - com graus variáveis de consciência - de lutas políticas que redefinem de modo contínuo as correlações de força, hierarquias e ordenamentos existentes. Essas lutas políticas, complexas e sutis, embora às vezes brutais, envolvem dimensões simbólicas, recursivas, morais e afetivas. Seu caráter político remete ao fato de que determinadas forças, sanções e decisões são soberanas, inescapáveis e sancionáveis - em cada espaço de trabalho -, reiteradamente estabilizando - ou recriando - hierarquias, correlações de força e formas de exercício de poder e de equacionamento de conflitos (Sartori, 1994) ${ }^{1}$. Nesse contexto, o que está em jogo para cada bancário é a possibilidade de permanecer e ascender em seu espaço de trabalho, auferindo reconhecimentos e contrapartidas materiais e imateriais, ocupando posições, vivenciando trajetórias significativas no âmbito existencial e horizontes de sentido partilhados e constituindo vínculos capazes de dotar de segurança seu trabalho e sua vida ${ }^{2}$.

É professor adjunto na Universidade da Integração Internacional da Lusofonia Afro-Brasileira (Redenção, CE). E-mail: eduardomachado@unilab.edu.br.

"Soberanas no sentido de poderem se sobrepor a qualquer outro poder; inescapáveis [...] porque se estendem até as fronteiras que definem territorialmente a cidadania [o microcampo, no caso analisado]; sancionáveis pois "sustentadas pelo monopólio legal da força" (Sartori, 1994, p. 287-8).

2 Mesmo que se trate de uma segurança provisória e instável, como discutem Giddens (1991) e Sennet $(2012,2009)$. Acerca da apropriação, neste artigo, das categorias "contextos existenciais" $e^{\text {"horizontes }}$ de sentido", ver Pfaff e Weller (2010). 
Porém, essas lutas políticas cotidianas são muitas vezes invisíveis aos que não trabalham nesses espaços, o que enfatiza a importância de um arcabouço teórico-metodológico que fundamente a observação dessas práticas no trabalho.

É através das práticas interindividuais que os agentes redefinem vínculos e microcomprometimentos e equacionam conflitos e antagonismos, o que é essencial à reprodução do capital e do trabalho. Para identificar, registrar e analisar essas práticas interindividuais, enfocando questões e temas caros à ciência política, desenvolve-se aqui uma abordagem interdisciplinar, mobilizando referências teórico-metodológicas sociológicas ${ }^{3}$. Articulam-se categorias de Bourdieu (1996a, 1996b, 2001, 2003, 2004, 2005, 2007), com os espaços de trabalho sendo compreendidos como microcampos e as práticas como transações sociais disposicionalmente mediadas (Blanc, 2009; Foucart, 2008, 2004; Fusulier e Marquis, 2009; Gibout, 2009). Cabe registrar que enfocar a investigação nas situações concretas experienciadas pelos trabalhadores nos espaços de trabalho não implica desconsiderar analiticamente outras escalas, que também condicionam e compõem as ações sociais. Nessa perspectiva, o caráter micro da investigação não desconsidera: 1) condicionamentos estruturais e disposicionais; 2) causalidades interescalares. A esse respeito, Remy (2005, p. 84) destaca:

Se o ponto de partida da transação social é a situação de interação, não se deve negligenciar o peso de enquadramentos mais amplos [...] o enquadramento permite explicitar os constrangimentos e as oportunidades [...] No entanto, a definição do enquadramento depende do foco essencial da transação privilegiado pelo pesquisador. Este foco definirá a distinção entre a situação, seu enquadramento e seu contexto ${ }^{4}$.

O objetivo do artigo é a apresentação e discussão de lutas políticas cotidianas nos espaços de trabalho do Banco do Brasil (BB), através da

\footnotetext{
Dentre as questões e temas caros à ciência política, cabe destacar a reconstituição contínua e sempre contingente de mediações e ordenamentos que permitam reproduzir ordens sociais específicas, estabilizando hierarquias, correlações de força e formas de exercício do poder político. Dentre as referências sociológicas mobilizadas, cabe destacar: o caráter reflexivo, situado, sequencial e recíproco das ações sociais; o foco nas práticas interindividuais continuamente reestruturadas, no âmbito de interações face a face, e condicionadas objetiva e intersubjetivamente; as tensões entre a constituição reiterada de mediações institucionais que equacionem conflitos e antagonismos, ordenando as relações de poder; e as incertezas, contingências e mudanças - muitas vezes trans-escalares - próprias à contemporaneidade do capital e do trabalho (Bourdieu, 2007; 2004; 2001; 1996; Giddens, 1991).

Esta e as demais traduções que compõem este artigo foram efetuadas por mim.
} 
análise de situações concretas experienciadas pelos funcionários conforme as categorias de estabilidade e empregabilidade ${ }^{5}$. Sob a estabilidade, analisam-se formas de exercício do poder e de controle dos trabalhadores, assim como estratégias de sobrevivência de funcionários "rebeldes". Sob a empregabilidade, analisam-se lutas pela conquista de posições e pelo comando em um microcampo bancário. Por fim, e a par de outros resultados e considerações analíticas, discutem-se as formas assumidas pelos vínculos e microcomprometimentos, categorias importantes no âmbito das transações sociais nos microcampos do BB, antes e após sua reestruturação nos anos 1990.

Fui bancário no BB entre 1984 e 1997 e participei do movimento sindical nesse período. Desde 1994, pesquiso o trabalho e os trabalhadores bancários, com foco nas transformações das últimas décadas no BB. Os dados foram gerados por meio de análise documental, entrevistas semiestruturadas, depoimentos e da observação direta, participante e não participante, de microcampos do $\mathrm{BB}^{6}$. Alguns dados foram revisitados analiticamente, através de questões que evidenciam minhas atualizações teórico-empíricas, enquanto outros foram analisados pela primeira vez. A observação direta permitiu registrar e analisar situações e interações cotidiana, sequenciais e reciprocamente vivenciadas pelos agentes sociais. Se até 1997 realizei essa observação ainda trabalhando na empresa, assumindo caráter de observação participante, a partir de 2011 envolveu idas sistemáticas a um microcampo bancário específico, caracterizando-se como observação não participante ${ }^{7}$. As observações foram registradas em diários de campo e as entrevistas e depoimentos transcritos por mim $^{8}$. Essas transcrições e diários constituem o corpus básico aqui analisado.

\footnotetext{
Os funcionários são bancários recrutados a partir de seleção pública nacional. Para um entendimento mais qualificado de como se compreende as categorias estabilidade e empregabilidade nos marcos da literatura contemporânea, ver Machado (2012). Cabe indicar que a utilização dessas categorias envolve uma apropriação crítica da Teoria da Regulação, fundamentada pelo referencial teórico de Pierre Bourdieu $(2007,2004,2001)$. Tais categorias são entendidas como formas institucionais que permitem o equacionamento dos conflitos e antagonismos entre capital e trabalho, no marco de regimes de acumulação e regulação capitalistas específicos.

6 Foram coletados dados nos períodos de 1994 a 1997, de 1999 a 2002 e de 2011 a 2015.

7 Entre 1999 e 2002 não foi realizada observação direta. Sobre observação direta e observação participante, ver Haguette (1992) e Jaccoud e Mayer (2010).

8 Neste artigo, quando as citações envolvem dados gerados por meio de entrevistas, depoimentos e observações de campo, isso é indicado no próprio texto.
} 


\section{Microcampos, disposições e transações sociais no Banco do Brasil}

Os espaços de trabalho são "universos sociais relativamente autônomos" que detêm princípios de construção e mecanismos de reprodução específicos, desvelando-se enquanto microcampos de forças e de lutas onde "os agentes se enfrentam, com meios e fins diferenciados" (Bourdieu, 1996a, p. 49-50; Bourdieu, 2004 , p. 27, 24 e 50). No BB, os espaços de trabalho são conformados por estruturas e disposições sociais que possibilitam e constrangem as práticas cotidianas ${ }^{9}$.

As estruturas conformam posições e permitem o acesso diferenciado aos capitais - econômicos, políticos, sociais, culturais, intelectuais, estéticos, éticos, técnicos, simbólicos - nos microcampos (Bourdieu, 2004, p. 19; Thompson, 1981) ${ }^{10}$. Cada indivíduo participa de um microcampo ao ingressar em posições estruturalmente constituídas e, mais do que isso, ao sentir e/ou produzir forças e efeitos (Bourdieu, 2007, p. 31). Além disso, participar de um microcampo pressupõe a aplicação recursiva e motivacional de estoques de conhecimento e de habilidades continuamente mobilizados (Peters, 2006). Bourdieu (1996a, p. 42), referindo-se ao habitus, evidencia um senso prático, um conjunto culturalmente adquirido - no âmbito de estruturas sociais específicas - de preferências, princípios de visão e de divisão, estruturas cognitivas duradouras e esquemas de ação que orientam a percepção da situação e a resposta adequada. Thiry-Cherques (2006, p. 33) amplia a compreensão das disposições sociais, ou habitus, ao indicar como:

[o habitus é um] sistema de disposições duráveis e transferíveis, que funciona como princípio gerador e organizador de práticas e de representações, associado a uma classe particular de condições de existência. [...] É adquirido mediante a interação social e, ao mesmo tempo, é o classificador e o organizador desta interação. [...] É composto: pelo ethos, os valores em estado prático, não consciente, que regem a moral cotidiana [...][;] pelo héxis, os princípios interiorizados pelo corpo: posturas, expressões corporais, uma aptidão corporal que não é dada pela natureza, mas adquirida [...] [;] pelo eidos, um modo de pensar específico, apreensão intelectual da realidade [...].

As disposições sociais duráveis e transferíveis evidenciam recursos simbólico-cognitivos e estoques motivacionais através dos quais os bancários se tornam aptos a participar das transações cotidianas nos microcampos,

Ver Machado (2012) para identificação das estruturas que perpassam os microcampos no BB.

10 Estruturas tecnológicas, organizacionais, gerenciais e contratuais (Machado, 2012). 
ordenando sua percepção da realidade e formando suas decisões, sendo importante evidenciar três de suas dimensões. Em primeiro lugar, abrangem conteúdos culturais específicos - valores, conhecimentos e habilidades -, constituídos, difundidos e desenvolvidos social e historicamente por coletividades de trabalhadores, com base em experiências sistemáticas e em articulação com um patrimônio cultural mais amplo e interclassista. Em segundo lugar, articulam valores em estado prático, princípios interiorizados pelo corpo e modos específicos de pensar. Em terceiro lugar, envolvem processos e dinâmicas disposicionais que permitem a apropriação e aplicação de referências culturais coletivamente constituídas (Thompson, 1981; Thiry-Cherques, 2006; Gross, 2006; Peters, 2011, 2006; Lawrence, 2003).

As disposições impelem e permitem a cada bancário, a partir de sua trajetória, enfrentar os desafios cotidianos, interagir e definir a melhor postura e escolha em cada situação. Nesse sentido, é possível afirmar, com base em Bourdieu (1996, p. 15), que nos microcampos do BB se reproduzem - sob os regimes de estabilidade e a empregabilidade - agentes dotados de disposições duráveis que os tornam aptos e inclinados a realizar determinadas transações.

As transações são compreendidas como conjuntos de práticas que evidenciam ações reciprocamente ajustadas, efetivando jogos de cooperação através dos quais os indivíduos se inserem nos espaços de trabalho, enfrentando problemas e interpelações cotidianas. Assim, envolvem "complexos procedimentos individuais", dependentes do "aprendizado socializativo de 'regras e recursos' intersubjetivamente sustentados nos seus ambientes sócio-históricos de atuação" (Peters, 2011, p. 130). Foucart (2008, p. 123), enfatiza a transação como "processo pelo qual se elaboram compromissos práticos [...] que permitem a cooperação conflitual e a recriação permanente dos vínculos sociais”. Nessa perspectiva, a categoria transação:

[...] põe o acento sobre "a complexidade das situações cuja avaliação é semialeatória mais que sobre situações fortemente estruturadas e codificadas, sobre os processos implícitos de ajustamento constante entre os parceiros mais que sobre as negociações explícitas, sobre a produção progressiva dos padrões de interação pelos próprios parceiros mais do que sobre a preexistência de um quadro normativo rigidamente balizado, sobre a tensão entre o cálculo de interesse e a afirmação de sentido onde a segunda pode muito bem prevalecer, sobre a relativa confiança onde os parceiros se beneficiam mutuamente mais que sobre a concorrência entre rivais" [...] (Fusulier apud Foucart, 2008, p. 122). 
Dessa forma, as disposições impelem e habilitam a participação de bancários nas interações cotidianas, em espaços de possíveis continuamente modificados, e as posições interferem na distribuição de capitais, porém, somente nas transações concretas é que se redefinem reciprocamente, e em situação, as escolhas, ações e posturas interindividuais.

\section{Relações de poder e rebeldias sob a estabilidade}

Sob a estabilidade, os microcampos do BB foram demarcados por estruturas tayloristas e fordistas e formas hierárquicas militarizadas, evidenciando sistemas de poder autoritários e relações marcadas pelo distanciamento interpessoal $^{11}$. Ao mesmo tempo, e paradoxalmente, os funcionários percebiam-se como parte de uma grande família, compartilhando disposições sociais, contextos existenciais, horizontes de sentido e contrapartidas materiais e simbólicas de caráter fordista. Havia estabilidade nas posições constituídas, e a lógica que regia as transações cotidianas nos microcampos era a da subordinação à autoridade, do comportamento social adequado e do cumprimento das tarefas exigidas, em sua forma e volume cotidianos, esperando-se, em contrapartida, que a empresa mantivesse reconhecimentos e compensações materiais e simbólicas institucionalizadas. Nesse contexto de enfrentamento coletivo da exploração, subordinação e alienação capitalista -, foram essenciais a criação, a difusão e o fortalecimento das instituições, tradições e lutas sindicais, impactando as experiências vivenciadas e a reconstrução das identidades dos funcionários. Mais do que isso, a criação das mediações institucionais que permitiram que o emprego assumisse o significado de projeto de vida, com as relações de assalariamento fundando uma ascensão profissional e social, instaurando o que Bourdieu $(1979,1992)$ denomina futuro objetivo coletivamente partilhado. Sob a estabilidade, $a$ priori, todos os funcionários eram campeões e, portanto, tinham direito às garantias fordistas, desde que conseguissem manter o emprego ${ }^{12}$.

Carlos $(1996,1997)$ e Fabíola (1997) (informação verbal) expuseram as posturas e interações hierárquicas e distanciadas entre comissionados e pos-

Essas características são efeitos da influência dos militares, principalmente após o golpe civil-militar de 1964 e até 1988, na sociedade e no Estado brasileiro. Alguns termos bancários, como "plataforma", "retaguarda" e"bateria", expressam essa influência.

12 A conquista e manutenção dos reconhecimentos e compensações materiais e simbólicas agregados ao emprego dependiam da força sindical coletiva, embora uma parcela deles fosse alocada individualmente. 
tos efetivos, contrastando-as com as imagens de grande família ${ }^{13}$. Segundo Carlos $(1996,1997)$ (informação verbal):

O gerente geral situava-se em sala própria, inacessível aos demais funcionários, assumindo um distanciamento em relação a eles, não mantendo diálogo ou comunicação direta com os postos efetivos, relacionando-se com os subordinados, em termos de tarefas e rotinas de serviço, exclusivamente através das cadeias hierárquicas e dos demais comissionados.

Caso fosse exigida, por exemplo, a assinatura do gerente em alguma partida contábil ou documento, primeiro este teria de passar pelo comissionado da área, que o repassaria ao gerente setorial, e este, por fim, ao gerente geral, normalmente através de "menores auxiliares", estagiários que transportavam materialmente os documentos (diários de campo, 1994-1997).

A relação dos gerentes setoriais com os postos efetivos também refletia hierarquias e controles disciplinares rígidos (diários de campo, 1994-1997). Alguns gerentes setoriais situavam-se à frente da sala do gerente geral, em mesa colocada na chamada "plataforma", de onde podiam visualizar e controlar o movimento da agência ou setor (diários de campo, 1994-1997). No início do expediente, os funcionários dirigiam-se a essa mesa, "respeitosamente", para "assinar o ponto" (diários de campo, 1994-1997). Nesse momento, o comissionado efetuava um primeiro controle dos funcionários, observando, por exemplo, se suas roupas estariam adequadas, caso contrário ocorreria uma "chamada de atenção" ou, eventualmente, a suspensão do funcionário. Os comissionados podiam utilizar uma série de sanções - suspensões, advertência, severa advertência e demissão - instituídas e aplicadas por meio de processo administrativo (diários de campo, 1994-1997) ${ }^{14}$. Caso estivesse sob processo administrativo, o que não era tão raro para alguns, o funcionário se dirigia todo dia ao banco, devidamente vestido, para assinar o ponto na frente dos colegas e ser dispensado pela gerência setorial, o que ocasionava, como se pode imaginar, situações de constrangimento e humilhação, como revelou Carlos (1996, 1997, informação verbal).

${ }^{13}$ Os nomes utilizados neste artigo são fictícios, para preservar a identidade das funcionárias e funcionários entrevistados ou observ0ados. "Posto efetivo" é o termo utilizado rotineiramente, à época, para caracterizar o funcionário que não possuía cargos comissionados ou gerenciais e tampouco exercia funções específicas mais qualificadas, como a de caixa, por exemplo.

${ }_{14}$ O funcionário recebia envelope lacrado, confidencial, com prazo para resposta escrita. 
Carlos (1996, 1997, informação verbal) e Gustavo (1996, informação verbal) destacaram também a presença dos inspetores ou auditores, que periodicamente visitavam as dependências para investigar os processos de trabalho em suas características contábeis, financeiras, trabalhistas etc. e que detinham poder superior e autonomia em relação aos gerentes gerais. Causavam temor aos postos efetivos, aos comissionados e aos gerentes. A investigação se detinha sobre cada funcionário, de forma minuciosa, ao ponto de coletarem as "partidas contábeis" executadas e rubricadas por cada um, verificando sua adequação às normas e procedimentos listados nas chamadas "cartas circulares", nas quais estavam prescritas as rotinas de serviço (diários de campo, 1994-1997). De acordo com os depoimentos, esse controle extrapolava o âmbito interno da empresa e era "natural" que os inspetores colhessem informações junto a comerciantes etc., acerca da "vida social ou privada" dos bancários e, em seguida, interpelassem-nos, exigindo comportamentos e atitudes considerados compatíveis com o fato de serem funcionários do BB (Carlos, 1996, 1997; Gustavo, 1996, informação verbal). Carlos (1996, 1997, informação verbal) indica como vários eram interpelados por gostarem de "beberem nos bares, frequentarem 'cabarés' [prostíbulos], possuírem dívidas comerciais, serem taxistas" etc. Assim, o controle atingia o âmbito interno e externo à empresa e visava criar um trabalhador e um homem integrado, dependente e dedicado exclusivamente à empresa através de comportamentos, atitudes e valores considerados adequados e padrões. É patente o viés fordista desse tipo de intervenção, ao buscar um controle global sobre o trabalhador que extrapolava os microcampos e atingia sua vida familiar e pessoal. Isso evidencia o caráter moral inscrito nas relações de trabalho (Druck, 1999).

Nesse período, anterior à reestruturação dos anos 1990, as relações de poder e as situações de luta, demarcadas por modos de controle profundamente hierarquizados, também se caracterizavam por tensões e resistências que assumiam formas diversas, entre as quais - e de maneira mais ou menos explícita, a depender de cada bancária e bancário e das experiências vivenciadas - o tom irônico ou sarcástico e o bom humor, presentes transacionalmente em gestos, posturas e diálogos (diários de campo, 1994-1997). Também o enfrentamento aberto ou "fingir-se de doido" com funcionários e funcionárias, fazendo de conta que não estavam entendendo, desconsiderando ou menosprezando as ordens recebidas, mesmo que aparentemente 
as acatassem (diários de campo, 1994-1997). Os conflitos e contradições adquiriam maior densidade e resolutividade através de mobilizações e ações sindicais, principalmente em períodos de conflito aberto e em eventos como as greves (diários de campo, 1994-1997). Porém, as resistências tinham limitações em decorrência tanto da força das autoridades constituídas e das potenciais sanções como da forma assumida pelos vínculos sob a estabilidade, que terminava por estabelecer limites morais a certas coerções ou resistências. A partir da reestruturação dos anos 1990, esses limites foram bastante fragilizados ou destruídos, com os vínculos e microcomprometimentos assumindo outras formas, que serão expostas em outros tópicos (diários de campo, 2011-2015) $)^{15}$.

Questionei Carlos (1996, 1997, informação verbal) acerca das relações entre comissionados e gerentes e os postos efetivos que não teriam comportamentos sociais considerados adequados a um funcionário do BB. Interessava perceber como e por que a empresa tolerava os funcionários "rebeldes" - como ele próprio se denominava - e, ao mesmo tempo, quais os mecanismos utilizados por eles para criar situações e relações estáveis e intersubjetivamente toleráveis no banco. Cabia entender quais as estratégias utilizadas por bancários rotulados como "boêmios", "rebeldes" ou "cabarezeiros", por exemplo, em um período de gerenciamento taylorista e fordista. Os relatos de Carlos (1996, 1997, informação verbal) permitiram perceber que se do ponto de vista disciplinar esses bancários estavam sempre "sob a mira dos comissionados", em geral tornavam-se, para compensar, funcionários experientes, qualificados e competentes disposicionalmente na execução de uma gama importante de serviços. Caracteriza-se então uma apropriação competente de aptidões, valores e saberes práticos relevantes à reprodução do capital e do trabalho em cada microcampo bancário.

Várias vezes esses trabalhadores "assumiam papéis e funções considerados difíceis e desgastantes" como forma de compensar atrasos e outras faltas disciplinares (diários de campo, 1994-1997). O próprio Carlos (1996, 1997, informação verbal), por exemplo, revela que "cansou de passar réveillon dentro do banco", fechando contas e balancetes. Gustavo (1996, informação verbal) revela como ficou diversas vezes além do horário para fechar contas, além de assumir outras tarefas desgastantes e complexas. Os comissionados

15 O que sinaliza questões teórico-empíricas importantes, que não são, porém, objeto deste artigo. 
e gerentes setoriais necessitavam dos saberes e perícias desses trabalhadores para manter os processos de trabalho, evitar atrasos, erros e até eventuais prejuízos financeiros. Essas tensões decorrentes das faltas disciplinares eram equacionadas por transações que envolviam o comissionado e o posto efetivo em questão. Em casos mais delicados, outros comissionados e até gerentes setoriais, superiores na hierarquia, podiam participar dos diálogos e decisões, mas sem contato direto com o posto efetivo (diários de campo, 1994-1997).

No período de vigência da estabilidade, houve o caso de uma equipe de trabalho na qual foram agregados somente funcionários com perfil rebelde. Essa equipe era conhecida, ao mesmo tempo: 1) pelos atrasos, ausências e outras faltas disciplinares; 2) por ser a equipe exemplar em termos de perfeição e rapidez na execução de tarefas difíceis; 3) pelo entrosamento pessoal, união e combatividade sindical. Nesse período, começo da década de 1990, das dezenas de equipes no microcampo em questão, essa era a única em que todos os funcionários, inclusive o comissionado, participavam das greves e de outras manifestações sindicais. Além disso, era a equipe que geralmente executava as tarefas antes dos prazos e horários determinados. Carlos (1996, 1997, informação verbal) e Gustavo (1996, informação verbal), que pertenceram a essa equipe, declararam, revelando orgulho em suas falas, que, "por diversas vezes, o comissionado foi questionado acerca de faltas disciplinares, relativas, por exemplo, ao horário de expediente". Nesses momentos, segundo os mesmos bancários, o comissionado reivindicaria autonomia de trabalho, explicitando o "desempenho profissional da equipe". Cabe falar, portanto, em poder político, em capacidade de negociação, barganha e resistência, com legitimidade assentada em competências profissionais individuais e coletivas. Pedro (1996, informação verbal), que também pertenceu à equipe, revela que, após alguns meses, ela foi dissolvida pela administração, e os membros, dispersos em outras equipes.

\section{A reestruturação dos anos 1990 no Banco do Brasil}

Durante as últimas décadas, no Brasil, os bancos têm implantado inovações tecnológicas, organizacionais, gerenciais e contratuais que impactam - estrutural e intersubjetivamente - os agentes, relações, processos e espaços de trabalho em diversas ordens e escalas (Campello, 2004; Hoefel e Jacques, 2006; Jacques e Amazarray, 2006; Machado, 2012; Mendes, Costa e Barros, 2003; Palácios, Duarte e Câmara, 2002; Santos, 2009; Segnini, 1999; Silva, 
Pinheiro e Sakurai, 2007; Seeb-DF, 2013). As mudanças evidenciam a crise e a recriação do padrão até então prevalecente de acumulação e regulação do capital e do trabalho. Esse padrão era demarcado por formas de sociabilidade, de controle societário e de modos de organização, gestão e contratação do trabalho tayloristas e fordistas, associadas a tecnologias específicas (Machado, 2012; Antunes, 2002). Considerando o acirramento dos conflitos, das lutas e da força político-sindical dos bancários, a partir do fim dos anos 1970, essa reestruturação assume o sentido de fragilização da categoria, incorporando diversos mecanismos de precarização do trabalho (Machado, 2012).

$\mathrm{O}$ BB é a maior instituição financeira da América Latina, com $110 \mathrm{mil}$ funcionários, 53 milhões de clientes, cinco mil agências e 63 mil caixas eletrônicos (BB, 2015) ${ }^{16}$. Entre as décadas de 1930 e 1980, foi um dos grandes símbolos do Estado desenvolvimentista e do bem-estar no emprego no país, sendo seus funcionários um dos segmentos mais importantes da classe trabalhadora brasileira. Nesse período, constituiu-se a estabilidade, um regime de regulação do trabalho, no âmbito do taylorismo e do fordismo, que subordinou a força de trabalho à ordem capitalista, instituindo compromissos mútuos entre a empresa e os bancários. Pouco a pouco, o cargo de funcionário do banco tornou-se o paradigma do bem-estar no trabalho no país, cobiçado por outros trabalhadores no setor privado e público, o que evidencia a constituição de acordos parciais e comprometimentos mútuos entre os agentes do capital e do trabalho (Machado, 2012; Théret, 2003; Druck, 1999 ${ }^{17}$. No contexto das estruturas tecnológicas, organizacionais, contratuais e gerenciais socialmente constituídas, esses bancários conquistaram uma condição salarial que lhes garantia segurança financeira, estabilidade profissional e familiar e prestígio social. Cabe mencionar os "compromissos institucionais" que regulavam os conflitos, estabilizavam as relações de poder e as correlações de força entre capital e trabalho no BB (Théret, 2003, p. 234) ${ }^{18}$. A estabilidade se tornou, então, uma forma eficaz

${ }^{6}$ Trata-se de uma empresa de economia mista controlada majoritariamente pelo governo federal.

7 A constituição da estabilidade e a reestruturação dos anos 1990 não promoveram a superação da exploração, da alienação e da subordinação do trabalho ao capital, na empresa, como evidenciado em Machado (2012). Para maiores esclarecimentos acerca de como se compreende o taylorismo e o fordismo, ver Machado (2012).

18 Neste artigo, diferentemente da Teoria da Regulação clássica, avalia-se que as vivências dos conflitos e antagonismos nas empresas bancárias - inclusive nas escalas dos espaços e dos cotidianos de trabalho, e instituindo mediações institucionais que os equacionem - situam-se para além de normas e regras, pressupondo um complexo e amplo espectro de disposições sociais articuladas a cada modo 
de equacionamento dos conflitos e de integração material, disposicional e simbólica de funcionários. Seus enquadramentos institucionais e mediações disposicionais proporcionavam um "contexto de longo prazo", a partir do qual o bancário tratava suas experiências, interagia transacionalmente e reconstituía vínculos e microcomprometimentos nos espaços de trabalho (Bourdieu, 1996a, 1996b, 2001, 2003, 2004, 2005, 2007; Thompson, 1981; Foucart, 2004, 2008; Gross, 2006; Sennet, 2012).

Nos anos 1990, em um contexto de hegemonia neoliberal, reestruturação produtiva e inserção subordinada do país na mundialização do capital, o BB vivenciou complexas inovações tecnológicas, organizacionais, gerenciais e contratuais (Harvey, 1993; Chesnais, 1996; Alves, 2000). As mudanças, ao atualizarem as formas de exploração e subordinação do trabalho, compuseram a longa gênese e evolução das relações, processos e tecnologias capitalistas na empresa (BB, 1990, 1994, 1996a, 1996b; Dieese, 1980, 1996, 1997, 1998a, 1998b; Eboli, 1992, 1997; Gennari, 1995; Grisci e Bessi, 2004; Jinkings, 1995, 1998; Machado, 1998, 2012; Maia, 1997; Maia Filho, 1998; Medeiros, 1996; Pagotto, 1996; Rodrigues, 2001; Segnini, 1999). São atualizados os modos de exploração e subordinação do trabalho, ampliando e agravando violências, sofrimentos e adoecimentos na empresa (Dejours, 1999, 2005). Embora não se possa falar em uma descontinuidade absoluta em relação aos padrões tayloristas e fordistas, cabe indicar que houve rupturas importantes nas mediações que regulavam as relações entre capital e trabalho, sob o regime de estabilidade $^{19}$. Emergiu um padrão flexível e toyotista de acumulação e regulação do capital e do trabalho no banco, que reequacionava as contradições capitalistas, as relações de poder e as correlações de força (Machado, 2012; Antunes, 2002). As consequências das mudanças envolvem a fragilização das entidades sindicais e das formas de organização do trabalho, a ampliação da exploração e da produtividade do trabalho, o desemprego, a restrição e a eliminação de direitos e perdas salariais (Machado, 2012).

\footnotetext{
de acumulação e regulação do capital e do trabalho (Conceição, 2002, p. 133).

19 As continuidades e descontinuidades que compuseram a reestruturação não são discutidas aqui, por questões de foco e limite do artigo. Dentre os programas, projetos e ações desenvolvidos: Novo Modelo Organizacional das Agências (1988-1989); Novo Rosto do Banco do Brasil (1990); Macrofunção de Pessoal (1993); listas de excedentes (1995-1996); Programa de Qualidade Total do Banco do Brasil (1994); Programa de Desligamento Voluntário (1995); Captura de Dados na Origem (1995-1996); BB-Net (1996); Automação Integrada de Agências (1996); Plano de Adequação de Quadros (1996-1997); Banco do Brasil na Hora da Verdade (1996-1997); Profissionalização (1996); Remuneração Variável (1996); mudanças no Plano de Cargos e Salários (1996); demissões imotivadas (1996-1997); Projeto de Qualidade (1996) (BB, 1990, 1994, 1996a, 1996b, 2014, 2015).
} 
No decorrer da reestruturação, as mediações disposicionais consolidadas não mais permitem aos trabalhadores responder adequadamente às interpelações e às exigências cotidianas nos microcampos, mediar conflitos e redefinir contínua e complexamente - em situação e interação - as escolhas e posturas adequadas. Os funcionários não dispunham mais, portanto, dos recursos - cognitivos, afetivos, corporais, técnicos, entre outros - e das referências morais e simbólicas que lhes permitiam participar de transações sociais múltiplas e complexas, pelas quais eram até então reconhecidos como jogadores competentes. Nessa perspectiva, a reestruturação dos anos 1990 instaurou uma situação de crise no BB, entendida como:

[...] uma situação coletiva caracterizada pelas contradições e rupturas, permeadas de tensões e desacordos, que tornam os indivíduos e os grupos hesitantes sobre a linha de conduta a seguir, porque as regras e as instituições socialmente estabelecidas retraíram-se ou estão até mesmo defasadas, considerando-se as possibilidades geradas a partir dos novos interesses e ideias que surgem através das mudanças, sem que se possa ainda pronunciar claramente sobre a justeza e a eficácia dos novos caminhos (Freund apud Foucart, 2004, p. 10).

A reestruturação modificou: 1) as expectativas, motivações e contrapartidas materiais e simbólicas; 2) os modos de reconhecimento; 3) os horizontes de sentido e contextos existenciais em operação no banco ${ }^{20}$. A essas mudanças se associaram, obrigatoriamente e sob o risco de fracasso, a criação e difusão de outras mediações disposicionais, que ampliaram as exigências corporais, mentais, intersubjetivas, afetivas, sociais, simbólicas, técnicas e culturais, dentre outras, requeridas nos espaços de trabalho (diários de campo, 2011-2015; Sennet, 2009; Thompson, 1981). No cotidiano do trabalho bancário, na contemporaneidade, a cada dia requer-se a mobilização e o desenvolvimento de um conjunto amplo e complexo de disposições sociais. Dois exemplos ilustram isso (diários de campo, 2011-2015). Um envolve as habilidades para perceber, em situação e rapidamente, mensagens implícitas passadas por colegas, mudanças nos equilíbrios e correlações de força, oportunidades de reinserção nas hierarquias existentes e potenciais alianças. Outro remete aos saberes,

20 A reestruturação não significou, a priori, a negação absoluta das formas tayloristas e fordistas existentes. Porém, essa discussão não será feita neste artigo. 
aptidões e habilidades que transcendem o trabalho prescrito, em um contexto de constantes mudanças nas posições e funções ocupadas e de grande amplitude dos produtos e serviços executados.

As exigências contemporâneas impactam extensa e intensivamente os corpos e mentes dos bancários, para além de dinâmicas e limites adequados à preservação da saúde. Trata-se de um contexto, pós-reestruturação, demarcado por múltiplas e complexas pressões e demandas, além de instabilidades, incertezas e riscos, onde os bancários vivenciam sofrimentos variados no trabalho e a partir do trabalho (Mendes, Costa e Barros, 2003; Palácio, Duarte e Câmara, 2002; Silva, Pinheiro e Sakurai, 2007; Chanlat Apud Jacques e Amazarray, 2006, p. 98; Pierson, 2011, p. 359). Não é à toa que vários funcionários tiveram dificuldades para se adaptar às novas exigências e pressões (Machado, 1997, 2015). Ao adaptarem-se, inscreveram-se em um cotidiano de pressões, expectativas e demandas múltiplas - advindas de segmentos gerenciais, colegas de trabalho, familiares, de si próprios e de clientes -, de horários fixos para a finalização das tarefas, além das exigências objetivas inscritas em equipamentos, máquinas e sistemas ${ }^{21}$.

\section{Sob a empregabilidade: lutas por posições no microcampo}

A partir da reestruturação dos anos 1990, associam-se ao contexto descrito a conquista e a manutenção de clientes e a venda de produtos e serviços; essas práticas formam a base material que fundamenta a lógica do produtivismo, redefinindo e acirrando os interesses em disputa e as competições interpessoais e coletivas nos microcampos bancários (diários de campo, 2011-2015). No BB, especificamente, as expectativas, motivações e contrapartidas materiais e simbólicas foram alteradas pelas novas políticas de remuneração, controle, avaliação e ascensão profissional. Assim, os rendimentos, reconhecimentos e posições passaram a depender cada vez mais da rentabilidade e da produtividade auferidas individual e coletivamente. Por isso, aqueles que antes eram vistos como campeões passaram a ser somente funcionários que atingem e superam metas, exigências interdisposicionais e objetivamente impostas, em microcampos onde se modificam os móveis de interesse e os investimentos efetivados:

\footnotetext{
Palácios, Duarte e Câmara (2002, p. 848) permitem evidenciar como é patente, para além das hierarquias institucionais, o controle interpessoal, com os colegas exercendo uma "fiscalização rigorosa, embora velada" no mundo do capital e do trabalho na contemporaneidade.
} 
[...] há tantos interesses quanto campos, enquanto espaços de jogo historicamente constituídos, com suas instituições específicas e suas leis próprias de funcionamento. A existência de um campo especializado e relativamente autônomo é correlativa à existência de alvos que estão em jogo e de interesses específicos: através dos investimentos indissoluvelmente econômicos e psicológicos que eles suscitam entre os agentes dotados de um determinado habitus, o campo e aquilo que está em jogo nele [...] produzem investimentos de tempo, de dinheiro, de trabalho etc. (Bourdieu, 2004, p. 126-7).

Analiticamente, cabe apontar "uma ordem oculta e não diretamente perceptível pelos sentidos”, envolvendo transações cotidianas: 1) pautadas por questões concretas; 2 ) mediadas por horizontes de sentido e disposições compartilhados; 3) vividas em enquadramentos de conflitos e conciliações sucessivas; 4) capazes de recriar vínculos e microcompromissos (Elias, 1994, p. 21; Pierson, 2011, p. 358-9; Foucart, 2004, 2008). A segmentação dos clientes evidencia elementos importantes dessa "ordem oculta" ao delimitar estruturalmente a competição nos microcampos do BB (diários de campo, 2011-2015). No BB, entre 2013 e 2014, de forma geral, os clientes são divididos em perfis ( $\mathrm{A}, \mathrm{B}, \mathrm{C}, \mathrm{D}$ e E), considerando-se critérios como a renda bruta anual, a renda mensal e o investimento ${ }^{22}$. Essas estruturas de segmentação delimitam hierarquias e posições, restringindo os clientes que serão atendidos por determinado funcionário ou grupo de funcionários ${ }^{23}$.

Cotidianamente, há metas institucionais, coletivas e individuais a serem cumpridas, campanhas ocasionais ou sazonais decididas em diversos níveis institucionais, a partir das informações geradas e avaliadas sistematicamente. As posições, cargos e funções ocupadas estruturam de maneira desigual o acesso de cada funcionário à intranet e às informações dos clientes, assim como as prerrogativas que possuem para realizar procedimentos, contratos e operações nos microcampos (diários de campo, 2011-2015). Além disso, conhecimentos e habilidades diferenciadas, entre os indivíduos, aplicados ao manejo de equipamentos, sistemas e aplicativos e à realização de procedimentos, fundamentam barganhas, vínculos e microcomprometimentos diversos (diários de campo, 2011-2015). Tudo isso se enquadra em uma lógica paradoxalmente marcada por compe-

22 O segmento A tem maior renda e investimento, que decrescem nos demais.

23 Para exemplificar as distinções no atendimento bancário, Grisci e Besci (2004, p. 185) diferenciam a gestão da intimidade e a gestão do anonimato no atendimento aos clientes. 
tições e, ao mesmo tempo, pela necessária e contínua reconstituição de vínculos e microcompromissos envolvendo bancários e clientes (diários de campo, 2011-2015).

Com base nessas referências, cabe analisar uma situação no microcampo investigado (diários de campo, 2011-2015). No salão principal da agência, o grande espaço de estar e de circulação, a estruturação socioespacial das posições revela uma divisão competitiva hierarquizada em três grupos. A ordem de ascensão profissional na ocupação das posições/mesas progride de fora para dentro do salão. Do lado esquerdo de quem chega ao salão, situa-se um grupo de quatro mesas, com funcionários que atendem o segmento popular dos clientes. Do lado direito está outro grupo, com três mesas, que atende os clientes intermediários ${ }^{24}$. Ao centro, de frente para a entrada, situa-se o atendimento dos clientes considerados a elite, com o gerente geral, o funcionário que o substitui em suas ausências (aqui chamado de subgerente) e uma terceira funcionária.

A situação se inicia com a chegada de um cliente com variados negócios e de maior renda à agência (diários de campo, 2011-2015) ${ }^{25}$. O cliente estabelece um diálogo cordial com o gerente geral e o subgerente, com saudações e brincadeiras mútuas. Porém, os dois bancários estão ocupados, assim como a terceira funcionária do grupo. Nesse quadro, uma funcionária recém-chegada à agência, situada na cadeira mais externa do grupo que atende os clientes populares, percebendo a situação, toma a iniciativa e se dispõe a atender o cliente. Este olha para os gerentes e, sem nenhuma reação ou indicação deles, se senta à mesa da funcionária. Inicia-se o atendimento e surgem dúvidas, pois a funcionária não está segura sobre como proceder, qual sistema utilizar e as rotinas e procedimentos a seguir. Levanta-se algumas vezes, anda em direção aos dois outros grupos, circula pelo salão, sorridente, entremeando perguntas e tentativas de diálogos com brincadeiras e falas leves, expondo o caráter dinâmico, espontâneo e agradável de sua presença. No decorrer

${ }^{24}$ Ao iniciar o atendimento e inserir os dados do cliente no sistema, o funcionário imediatamente tem acesso a informações sobre a situação dele. Além disso, pode fazer simulações diversas, envolvendo os produtos e serviços bancários. Cabe ao funcionário, nos termos das orientações gerais da empresa e do planejamento da dependência, em cada contexto, escolher as opções adequadas e vender os produtos e serviços, convencendo o cliente etc.

25 A segmentação dos clientes segue basicamente a mesma lógica em todas as agências do banco. Assim, embora somente uma situação tenha sido analisada, considera-se que ela evidencia elementos importantes, ao tensionar a hierarquia, a correlação de forças e os vínculos estabelecidos e reproduzidos no espaço de trabalho. 
da situação, a funcionária que atende os clientes de maior renda vai percebendo e interpretando a postura da recém-chegada como uma ameaça ou, pelo menos, como uma intromissão indevida. A funcionária novata, sempre interagindo com o cliente, expõe gestos, posturas e falas agradáveis, contrapondo-se imageticamente à funcionária que tem a posição ameaçada, que permanece sentada, rígida, nervosa, fechada.

A nova funcionária tenta por um caminho, não recebe resposta, senta, retorna, inicia um diálogo com outro funcionário, do grupo intermediário, não consegue, e assim segue por dez a quinze minutos, buscando abrir interlocuções e realizar os procedimentos de trabalho (diários de campo, 2011-2015). Há pequenas indicações, muito cuidadosas, do subgerente e de um funcionário do segmento secundário, que evitam significar algum tipo de comprometimento. A funcionária segue as orientações indicadas, porém, claramente há barreiras, provavelmente relacionadas às senhas exigidas e aos níveis de acesso dos sistemas, que variam de acordo com o segmento atendido e a função ocupada. Há uma tensão no ar e, apesar de continuarem realizando suas tarefas, os colegas sentem e percebem intuitivamente o que está em jogo. Todos relutam em assumir uma posição explícita. O subgerente parece indeciso, mantém uma postura tranquila e agradável, mas não cede no essencial - a resolução do procedimento, que é a mediação para a conquista da posição. A disputa envolve uma posição consolidada e importante na hierarquia da agência. Após algum tempo, e sem conseguir resolver a situação, o cliente passa a ser atendido pelo subgerente (diários de campo, 2011-2015).

A análise permitiu perceber como as transações evidenciam uma constante reapropriação e ressignificação da situação pelos agentes envolvidos, como em um jogo de esgrima, no qual as iniciativas e ações - os golpes - são recebidos, aparados, desviados, enquadrados, defesa e ataque sucedendo-se continuamente. Mais do que isso, a observação evidenciou a complexidade e a sutileza das transações, com variadas linguagens e disposições mobilizadas. Borzeix (2001, p. 50-1), em uma perspectiva epistemológica que valoriza a presença da palavra - e, mais amplamente, das diferentes linguagens - e a ampliação de seus usos e funções nos espaços de trabalho, abre espaço para analisar a complexidade das situações e interações vivenciadas pelos 
trabalhadores ${ }^{26}$. Diferentes linguagens - por exemplo, oral, corporal, gestual, escrita, imagética, entre outras - compõem as lutas políticas cotidianas nos espaços de trabalho bancários contemporâneos (Borzeix, 2001, p. 49-50).

Outra percepção importante é a de que as disposições da empregabilidade, utilizadas como recursos de poder, são também propulsores intersubjetivos para as lutas que envolvem a conquista de posições e a reinstituição de vínculos e comprometimentos no microcampo. Essa forma de compreensão das transações sociais, portanto, não exclui a priori ou de maneira absoluta a presença de motivações e intencionalidades intersubjetivas nas práticas concretas dos bancários. Embora as segmentações dos clientes revelem seu caráter estrutural a constranger as transações, também há "estoques motivacionais" que propelem interdisposicionalmente as transações ${ }^{27}$. Nesse sentido, Peters (2006, p. 40) afirma:

O caráter socialmente situado e condicionado dos estoques motivacionais que movem a ação individual deriva do fato de que essas motivações subjetivas não constituem essências antropológicas trans-históricas, sendo, na verdade, geradas, mantidas e/ou eventualmente transformadas a partir da contínua inserção do indivíduo em uma rede de relações sociais e em teias pré-constituídas de significações simbólicas [...].

Em outras visitas à agência, observou-se que a nova funcionária e a funcionária com a posição ameaçada permaneciam ocupando as mesmas posições (diários de campo, 2011-2015). A partir das experiências vivenciadas e das potencialidades, frustrações e derrotas envolvidas, houve modificação nas expectativas e motivações da nova funcionária, que assumiu postura mais retraída, evitando expor-se e participar diretamente das disputas políticas mais acirradas no microcampo.

\section{Sob a empregabilidade: lutas pelo comando no microcampo}

Aproximadamente um ano após essa situação, o gerente geral foi remanejado para outra agência e um funcionário vindo de outra dependência assumiu o cargo, observando-se insatisfações de alguns bancários com essa mudança (diários de campo, 2011-2015). A troca do gerente geral impactou

\footnotetext{
${ }^{26}$ É possível trabalhar com alguns insights dessa linha analítica sem necessariamente compartilhar sua perspectiva teórico-metodológica e epistemológica.

27 Para aprofundamento dessas questões teórico-epistemológicas, ver Peters (2006).
} 
o campo do poder, gerando tensões, evidenciando a existência de dois grupos em disputa e constituindo potencialidades de alteração na hierarquia dominante e no comando do microcampo. Outro episódio evidencia esse quadro (diários de campo, 2011-2015).

O novo gerente geral, ao sair de férias, designou como seu substituto não o funcionário que naturalmente deveria assumir o cargo, denominado aqui de subgerente, que senta ao seu lado na agência e é responsável pelo segmento mais elitizado dos clientes (diários de campo, 2011-2015). Ao contrário, o gerente geral designou o comissionado responsável pelos segmentos médios de clientes, demarcando insatisfações, aproximações, distanciamentos e disputas. As tensões se agravaram, com as iniciativas destinadas a disputar e manter clientes evidenciando dois estilos de trabalho a gestar legitimações político-simbólicas (diários de campo, 2011-2015).

O novo gerente geral parece pretender imprimir a marca de desempenho técnico qualificado como elemento essencial ao microcampo, exigindo consistente qualificação dos funcionários, a ser demonstrada nos procedimentos de trabalho (diários de campo, 2011-2015). A perícia técnica, o saber fazer informal, a capacidade para enfrentar imprevistos, a variabilidade, a iniciativa para resolver problemas parecem se destacar como recursos de poder e capitais a potencialmente determinar mudanças institucionais e simbólicas nas hierarquias e no sistema de poder. Por outro lado, o grupo parcialmente derrotado parece querer assentar seus domínios e sua segurança em uma capacidade de interlocução com os clientes, destacando como recursos de poder a simpatia, o contato leve, espontâneo e sempre renovado em suas capacidades de lidar com cada pessoa de maneira adequada à sua posição social, ao seu prestígio e às suas exigências. Assim, através de pequenos favores, gentilezas e brincadeiras, esses funcionários buscam reativar continuamente vínculos e alianças informais, conquistando a empatia e a boa vontade dos clientes ${ }^{28}$.

Desvelam-se dois estilos de luta política, com tensões entre saber fazer e perícia técnica, de um lado, e capital social do outro (diários de campo, 2011-2015). Embora ambos os segmentos necessitem dispor de conhecimentos, habilidades e valores que lhes permitam efetuar as transações no microcampo, há diferenças relevantes entre as lideranças individuais em luta

${ }^{28}$ Cabe indicar que a agência possui um número relevante de clientes com prestígio social, renda alta e posições de poder importantes na sociedade. 
(Lahire, 2005). O funcionário que chegou ao cargo superior como substituto já se destacava, em situações anteriores, pela perícia técnica, pelo conhecimento de vários sistemas e processos de trabalho e pela capacidade de lidar com problemas, imprevistos e variáveis cotidianas. Não poucas vezes foi chamado por colegas, inclusive pelo subgerente, para ajudar em procedimentos e rotinas bancárias, dirimindo dúvidas, aplicando e repassando conhecimentos. Ao mesmo tempo, embora a outra liderança - o subgerente - detenha certo grau de perícia técnica, destaca-se pela capacidade espontânea de criar um clima aparentemente agradável no espaço de trabalho, conversando e brincando com os clientes, reconhecendo suas idiossincrasias e sabendo lidar com cada uma delas.

Outras situações observadas revelam o que está em disputa no microcampo (diários de campo, 2011-2015). Em uma delas, a funcionária que compõe o grupo de poder que se fragilizou, antes de sair de férias, em diálogo com uma cliente, pediu a ela que fizesse suas operações com o subgerente, indicando explicitamente que não as fizesse com o comissionado dos segmentos médios. Esse comissionado vinha investindo para se aproximar dessa cliente, que havia informado que realizaria uma aplicação relevante no banco durante as férias da funcionária. Esse caso revela a disputa pelos clientes, pela realização de negócios como móvel objetivo que media interdisposicionalmente as disputas políticas no microcampo. Nessa situação específica, a cliente realizou a operação com o comissionado dos segmentos médios, no exercício da gerência geral, em certa medida por iniciativa do próprio funcionário, que, ao perceber a cliente na agência, estabeleceu logo um contato, atendendo-a imediatamente.

No decorrer dessa situação de atendimento, dois momentos evidenciam as tensões e conflitos que perpassam pelos procedimentos de trabalho, nesse quadro de disputa pelo comando do microcampo (diários de campo, 2011-2015). O subgerente, sentado ao lado do gerente geral em exercício, várias vezes dialogou amigavelmente com a cliente, fez pequenas brincadeiras, reativou lembranças e situações vivenciadas, a fim de demarcar sua presença e manter os vínculos abertos. Por sua vez, o gerente geral em exercício, em certo ponto do atendimento perguntou ao subgerente se este tinha realizado determinado procedimento. $\mathrm{O}$ subgerente ficou em silêncio por um instante e em seguida disse: "Não, esqueci". Respondeu laconicamente, de maneira tensa e até mesmo provocativa e desafiadora, a questionar o comando, a hierarquia, causando constrangimento ao gerente geral ao assumir uma postura de deslegitimação da autoridade. 
A designação do comissionado do segmento médio para substituir o gerente geral rompeu a hierarquia consolidada, causando surpresas e constrangimentos no microcampo (diários de campo, 2011-2015). Funcionárias e funcionários demonstraram dificuldades para lidar com esse novo enquadramento hierárquico, e alguns, não envolvidos de maneira mais orgânica nas disputas de poder, comentavam: "Fulano está com tudo!" Ao mesmo tempo, o subgerente, vivenciando e também buscando causar constrangimentos, assumiu uma postura desafiadora e, no limite, ofensiva, exacerbando sua movimentação pela agência e os contatos e diálogos com os clientes, constituindo-se em contraponto e alternativa, inclusive física e espacialmente, ao gerente geral em exercício.

As proximidades e distâncias físicas são relevantes nas lutas políticas, com o sentar ao lado e o ocupar mesas vizinhas, por exemplo, revelando-se elemento de poder e, ao mesmo tempo, gerando constrangimentos e tensões (diários de campo, 2011-2015). Cada líder busca aproximar de si aliados e potenciais aliados no decorrer do dia e nas várias situações enfrentadas. $\mathrm{O}$ gerente geral em exercício, por exemplo, em determinado ponto do atendimento chamou a funcionária que fora o pivô da primeira situação descrita, já não mais tão novata na agência, e fez a ela algumas perguntas, buscando envolvê-la no processo. Porém, ela não desenvolveu a conversa, não respondeu a contento, parecendo um pouco constrangida em participar do atendimento, o que pode indicar que ela não possuía as informações, habilidades e conhecimentos necessários ao atendimento ou que não quis tomar partido nessa disputa. As observações sugerem que, exposta às lutas políticas no microcampo, com seus riscos e impactos, aquela funcionária, diante das resistências, sanções e sofrimentos vivenciados, reconstituiu sua identidade, modificando as disposições interiorizadas e aplicadas transacionalmente.

\section{Considerações finais}

[...] poder-se-ia dizer que a disposição é exposição. Justamente porque o corpo está (em graus diversos) exposto, posto em xeque, em perigo no mundo, confrontado ao risco da emoção, da ferida, do sofrimento, por vezes da morte, portanto obrigado a levar o mundo a sério (e nada é mais sério do que a emoção, que atinge o âmago dos dispositivos orgânicos), ele está apto a adquirir disposições [...] (Bourdieu apud Wacquant, 2002, p. 103). 
As disposições impelem e potencialmente habilitam o ingresso, a permanência e a ascensão nos microcampos. Porém, é somente nas situações concretas que se redefinem as escolhas, ações e posturas, com o caráter transacional das práticas evidenciando complexidades e sutilezas e, mais do que isso, sua contínua tensão pelo implícito, pela incerteza e pela mudança. Bancárias, bancários e clientes interagem sistematicamente no microcampo, face a face, condicionados por constrangimentos estruturais e apropriados de disposições sociais que promovem ações e estratégias, reciprocamente mediadas, desvelando o caráter reflexivo, embora não obrigatoriamente intencional e consciente, das ações sociais (Foucart, 2008, 2004; Bourdieu, 1996a, 1996b, 2001, 2003, 2004, 2005, 2007). Nesse sentido, cabe entender que, a par de certa continuidade, os recursos apropriados e aplicados e os móveis das ações - fins, motivações, intenções - são reconstituídos, individual e coletivamente, no decorrer das experiências vivenciadas (diários de campo, 2011-2015).

Como é possível evidenciar, há toda uma dimensão política imperceptível aos não iniciados, aos não participantes do microcampo, a qual envolve jogos, estratégias e interesses e manifesta o caráter complexo, sutil, mas, em alguns casos, violento e até brutal, das transações cotidianas. Em cada microcampo, as transações revelam seu caráter político na medida em que é por meio delas que cada bancário pode: 1) ocupar e manter posições, desenvolvendo trajetórias individuais e ascendendo nas hierarquias formais e informais; 2) tomar partido nas escolhas interindividuais; 3) participar das lutas cotidianas, inclusive acessando mecanismos de equacionamento de tensões e conflitos; 4) constituir e manter vínculos interindividuais, efetuando micropactuações implícitas e explícitas; 5) compor processos de reconhecimento e distinção, reconstituindo horizontes de sentido, expectativas e motivações individuais e coletivas; 6) requerer, auferir e conceder contrapartidas materiais e imateriais; 7) lidar com fontes e dinâmicas de sofrimento no trabalho.

Sob o regime de estabilidade, o distanciamento e a reserva hierárquicos, paradoxalmente associados à ideia de grande família, foram características estruturais nos espaços de trabalho - gerentes, por exemplo, ocupavam salas fechadas, inacessíveis às funcionárias e funcionários comuns (diários de campo, 2011-2015). Nesse enquadramento, a reprodução de vínculos e microcomprometimentos interindividuais assumia duas formas (diários de campo, 2011-2015). Uma era vertical e envolvia pactuações entre postos efe- 
tivos e gestores em diferentes níveis hierárquicos, sempre através dos cargos e da cadeia formal de comando. Nela, diante de faltas, erros ou limitações, constituíam-se demandas e sanções a exigir contrapartidas que poderiam assumir a forma de tarefas e atividades específicas ou de comportamentos esperados. A outra forma, horizontal, não competitiva, assentava-se no ideário de grande família e agregava funcionários de mesmo nível hierárquico. Evidenciava, dessa forma, a amplitude da convivência nos espaços de trabalho e para além deles, no período anterior à reestruturação dos anos 1990 (Machado, 2012).

A reestruturação modificou os processos, as relações e os espaços de trabalho do BB, destruindo padrões de consumo e prestígio social, contextos existenciais, horizontes de sentido e contrapartidas materiais e simbólicas coletivamente partilhadas e desfrutadas por esses bancários e bancárias e suas famílias (Machado, 2012) ${ }^{29}$. Desde então, as resistências foram pouco a pouco quebradas, permitindo um doloroso e difícil processo de reconstituição identitária e de geração e difusão de novas disposições, que habilitaram os indivíduos a efetuar transações sob o regime da empregabilidade ${ }^{30}$. A produtividade e a competitividade tornaram-se valores essenciais, recriando-se as expectativas e motivações, instituindo-se a imagem do empreendedor competitivo e deslocando para o trabalhador a responsabilidade pela realização das tarefas e pela manutenção do emprego (Lima, 2010). A mecânica da luta nos microcampos passou a envolver, objetivamente, a disputa por segmentos de clientes, pela ampliação da produtividade e da rentabilidade e pelo cumprimento e potencial superação das metas existentes (diários de campo, 2011-2015). Intersubjetivamente, está em jogo a sobrevivência emocional, psicológica, simbólica e física dos bancários (diários de campo, 20112015). Como parte das mudanças, reconstituem-se acordos e pactuações horizontais e verticais, modificando-se as formas assumidas pelos vínculos e microcomprometimentos interindividuais (diários de campo, 2011-2015).

A partir da reestruturação dos anos 1990, até o gerente geral situa-se próximo a outros bancários, evidenciando a exacerbação do "estar exposto", com suas implicações sociopolíticas. Funcionários de todos os níveis hierárquicos

${ }^{29}$ Ver Bohnsack e Schäffer apud Pfaff e Weller (2010, p. 57).

30 Essa recriação das disposições e identidades pode permitir, inclusive, que o sofrimento, a dor, a doença e a perda possam desaparecer - invisíveis, embora em alguns casos bem presentes - ou fazer sentido e tornarem-se produtivos. 
participam das lutas políticas que transacionalmente impactam o exercício do poder, as correlações de força e os vínculos nos microcampos (diários de campo, 2011-2015). As novas formas potencialmente exacerbam as pressões sociais, envolvendo, para além dos mecanismos de coerção, dimensões e dinâmicas consensuais que tensionam as escolhas e os processos de formação das decisões nos microcampos (diários de campo, 2011-2015) 31. Agrega-se a esse quadro o fato de que no mundo contemporâneo do capital e do trabalho reforçam-se as tensões entre os pontos de apoio, as posições e as fronteiras continuamente demarcadas e as incertezas, os riscos e as mudanças ${ }^{32}$.

Uma hipótese analítica preliminar que pode ser aqui exposta, exigindo investigações e análises posteriores, é a de que tem se reforçado o caráter transacional das práticas dos trabalhadores e trabalhadoras - o que não significa que ele estivesse ausente no regime anterior. Muitas das negociações cotidianas nos microcampos da empresa, sob a estabilidade, envolviam postos efetivos e comissionados e reproduziam micropactuações e vínculos importantes, mas detinham caráter não explícito. Porém, sob a empregabilidade, a instauração de mecanismos horizontais de regulação e controle evidencia uma ampliação e uma complexificação das características transacionais destacadas por Fusulier e Marquis (2009, p. 28):

A noção de transação social chama a atenção sobre os múltiplos jogos entre o racional e a afirmação de sentido, o formal e o difuso, o contínuo e o descontínuo. A negociação enfatiza o peso das questões e problemas enfrentados, as estratégias em jogos de poder assim como a dialética da invenção. É fato que a transação social pode operar quando há a impossibilidade de efetivar uma negociação explícita.

Participar das lutas políticas tem seus riscos, consequências e exposições, particularmente em tempos de mudanças e na medida da alteração dos equilíbrios e correlações de força, das lógicas e dos interesses envolvidos. No BB contemporâneo, as situações tornam-se mais delicadas e complexas porque parte dos funcionários tem bastante tempo de casa, sendo sobreviventes da reestruturação dos anos 1990. Ao mesmo tempo, novas gerações inscrevem-

${ }^{31}$ No sentido dado por Gramsci (2002), consenso é entendido como "adesão voluntária", contraposto à coerção, entendida como imposição externa.

32 "[...] a ordem tem um imperativo: deve ser construída pelos homens para se evitar o caos e a barbárie, e, uma vez alcançada, ela não será definitiva, pois há sempre, em germe, o seu trabalho em negativo, isto é, a ameaça de que seja desfeita" (Sadek, 1991, p. 18). 
-se nos microcampos, às vezes com expectativas, motivações e disposições muito variadas e distintas em relação aos antigos. Assim, acumulam-se percepções, ressentimentos, empatias e antipatias, evidenciando a interligação de dimensões profissionais, pessoais e familiares nas situações cotidianas. Isso revela como as transações envolvem complexos de afetos, paixões e intersubjetividades, inclusive códigos morais, a interferir nas lutas políticas cotidianas e, ao mesmo tempo, aspectos mais técnico-disposicionais, que podem permitir ou não a conquista e o exercício do poder político. Por isso, não é a toa que alguns bancários assumem posturas de recolhimento e reserva em relação às lutas políticas no microcampo. Porém, mesmo os que buscam distanciar-se são afetados, vivenciando as implicações das vitórias e derrotas de diferentes grupos e lideranças.

Nos atuais microcampos do $\mathrm{BB}$, certos funcionários e funcionárias assumem papéis e funções preponderantes, tornando-se líderes capazes de redefinir estratégias e eixos de atuação e aglutinar forças (diários de campo, 2011-2015). Competições e disputas e, ao mesmo tempo, paradoxalmente, pactuações e vínculos interpessoais adquirem maior densidade e importância, ressignificando-se e refuncionalizando-se. Em cada microcampo, líderes e aliados demandam posicionamentos, buscando agregar apoios ou, pelo menos, neutralizar potenciais resistências e contraposições, a fim de ordenar o microcampo, recriar vínculos e microcomprometimentos e sustentar equilíbrios e correlações de forças.

As incertezas, contingências e instabilidades próprias tanto do mundo contemporâneo do capital e do trabalho como das dinâmicas e lutas políticas enfatizam que há sempre algo de transitório ou circunstancial nos ordenamentos estabelecidos (Sadek, 1991, p. 18; Chaia, 1995). Nesse quadro, o caráter transacional das lutas políticas cotidianas evidencia como, para além das derrotas e vitórias experimentadas, indivíduos e grupos em luta são obrigados a reproduzir vínculos e micropactuações que coobrigam limites de ação e reação, prerrogativas de poder e contrapartidas materiais e simbólicas reconhecidas como adequadas. Assim, o saber fazer político torna-se uma arte do possível, um agir transacional virtuoso, potencialmente capaz de recriar ordens, hierarquias e correlações de força em cada microcampo bancário, em um cenário de contínuas tensões entre o que pode permanecer e o que é fugaz (Gruppi, 1980; Bourdieu, 1996a, 1996b, 2001, 2003, 2004, 2005, 2007; Foucart, 2004, 2008). 
As mudanças articulam ambiguidades e paradoxos importantes. Recriam-se as formas de subordinação e de controle do trabalho, aperfeiçoam-se formas e mecanismos intersubjetivos de controle dos trabalhadores - em suas múltiplas dimensões disposicionais. Porém, produzindo resultados não esperados, as mudanças, ao reforçarem o caráter transacional das práticas cotidianas, tendem a ampliar os conflitos e lutas políticas nos espaços de trabalho, mesmo que nos marcos do produtivismo, da mercantilização e da competitividade.

O novo contexto constitui uma forma de regulação do trabalho distinta daquela anterior à reestruturação dos anos 1990, que, com o objetivo de despolitizar os espaços de trabalho, concentrava as negociações, a formação de vínculos e microcomprometimentos, o equacionamento de conflitos e a distribuição de contrapartidas materiais e imateriais nas mãos dos poucos bancários com cargos superiores na hierarquia formal dos microcampos. $\mathrm{Na}$ contemporaneidade, cada bancário precisa participar das lutas políticas se quiser sobreviver e ascender em seu microcampo: somente assim pode interferir na reconstituição de hierarquias e ordenamentos e na distribuição das contrapartidas que não são mais previamente garantidas e universais. Ocorre que, ao se envolver nas lutas políticas, cada bancário experiencia situações e interações sociais e, ao fazer isso, se educa politicamente, o que impacta a reconstituição das identidades individuais e coletivas, mesmo em seus aspectos classistas. Contudo, essa hipótese e suas potenciais consequências - inclusive em relação ao enfrentamento coletivo das contradições capitalistas - necessitam ser ainda investigadas.

\section{Referências}

ANTUNES, Ricardo (2002). "As novas formas de acumulação de capital e as formas contemporâneas do estranhamento (alienação)". Caderno CRH, n. 37, p. 23-45.

BLANC, Maurice (2009). "Lavenir de la sociologie de la transaction sociale". Recherches sociologiques et anthropologiques, v. 40, n. 2, p. 125-39. Disponível em: <http://rsa.revues.org/157>. Acesso em: 28 abr. 2014. BORZEIX, A. (2001). "Le travail et sa sociologie à l'épreuve du langage, et 'L'information-voyageurs en gare du Nord"', em BORZEIX, Anni \& FRAENKEL, Béatrice (orgs.). Langage et travail : communication, cognition, action. Paris: CNRS Éditions. 
BOURDIEU, Pierre (1979). O desencantamento do mundo. São Paulo: Perspectiva.

(1996a). Razões práticas: sobre a teoria da ação. Campinas, SP: Papirus.

(1996b). "Marginalia: algumas notas adicionais sobre o dom". MANA, v. 2, n. 2, p. 7-20. Disponível em: <http://www.scielo.br/pdf/mana/v2n2/ v2n2a01.pdf $>$. Acesso em: 28 mar. 2014.

(2001). Meditações pascalianas. Rio de Janeiro: Bertrand Brasil.

(2003). “A economia das trocas lingüísticas", em ORTIZ, Renato (org.). A sociologia de Pierre Bourdieu. São Paulo: Olho d’Água.

(2004). A economia das trocas simbólicas. 5. ed. São Paulo: Perspectiva. (2005). Esboço de auto-análise. São Paulo: Companhia das Letras. (2007). O poder simbólico. 10. ed. Rio de Janeiro: Bertrand Brasil. BB (1990). “O novo rosto do Banco do Brasil”. 22 out. Brasília: Banco do Brasil.

(1994). "Política de pessoal: estratégia da macrofunção pessoal". Brasília: Banco do Brasil.

(1996a). "A hora da verdade: plano de reestruturação do Banco do Brasil”. 20 mar. Brasília: Banco do Brasil.

(1996b). "Programa Profissionalização”. 8 jun. Brasília: Banco do Brasil.

(2014). "Rede de atendimento". Disponível em: < http://www.bb.com. br/portalbb/page251,101,500583,0,0,1,0.bb?codigoNoticia=41213\&cod igoMenu=225>. Acesso em: 15 jan. 2015.

CAMPELLO, Jacqueline Cunha (2004). Cargas de trabalho e evidências de seu impacto sobre a saúde de trabalhadores em bancos: estudo de caso em quatro instituições financeiras em Porto Alegre. Dissertação (mestrado) em engenharia. Porto Alegre: UFRS.

CONCEIÇÃO, Octavio A. C. (2002). “O conceito de instituição nas modernas abordagens institucionalistas”. R. Econ. Contemp., v. 6, n. 2, p. 119-46.

CORDEIRO, Valeska Rodrigues Velloso (2005). Atividade de atendimento ao público, treinamento e custo humano do trabalho: o caso dos gerentes de contas de uma instituição bancária. Dissertação (mestrado) em psicologia. Brasília: UnB.

DEJOURS, Christophe (1999), A banalização da injustiça social. Rio de Janeiro: FGV. 
(2005). Travaux préparatoires à l'élaboration du Plan Violence et Santé. Paris: Ministère de la Santé et des Solidarités.

DRUCK, Graça (1999). Terceirização: (des)fordizando a fábrica. Salvador: Edufba; São Paulo: Boitempo Editorial.

ELIAS, Norbert (1994). A sociedade dos indivíduos. Rio de Janeiro, Jorge Zahar.

FERREIRA, Mário César (2012). "Ergonomia da atividade aplicada à qualidade de vida no trabalho: saúde e promoção do bem-estar dos trabalhadores em questão". Revista Tempus Actas de Saúde Coletiva, v. 6, n. 12, pp. 61-78.

FOUCART, Jean (2004). "La souffrance: un enjeu social contemporain". Pensée plurielle , v. 2, n. 8, p. 7-20. Disponível em: <http://www.cairn.info/ revue-pensee-plurielle-2004-2-page-7.htm>. Acesso em: 28 abr. 2014.

FOUCART, Jean (2008). “Accompagnement et transaction: une modélisation théorique”. Pensée plurielle, v. 1, n. 17, p. 113-34. Disponível em: <http:// www.cairn.info/revue-pensee-plurielle-2008-1-page-113.htm>. Acesso em: 28 abr. 2014.

FUSULIER, Bernard \& MARQUIS, Nicolas (2009). “Transaction sociale et négociation : deux notions à articuler”. Négociations, v. 2, n. 12, p. 23-33. Disponível em: <http://www.cairn.info/revue-negociations-2009-2page-23.htm. Acesso em: 28 abr. 2014.

GIBOUT, Christophe et al. (2009). "Transactions sociales et sciences de l'homme et de la société”. Pensée plurielle, v. 1, n. 20, p. 7-11. Disponível em: <http://www.cairn.info/revue-pensee-plurielle-2009-1-page-7.htm. Acesso em 29 abr. 2014.

GIDDENS, Anthony (1991). As conseqüências da modernidade. São Paulo: Editora Unesp.

(2002). Cadernos do cárcere. v. 2. 2. ed. Rio de Janeiro: Civilização Brasileira.

GRISCI, Carmen Lígia Iochins \& BESSI, Vânia Gisele (2004). "Modos de trabalhar e de ser na reestruturação bancária". Sociologias, v. 6, n. 12, p. 160-200.

GRUPPI, Luciano (1980). Tudo começou com Maquiavel. 12. ed. Porto Alegre: L\&PM.

HAGUETTE, Teresa Maria Frota (1992). Metodologias qualitativas na sociologia. 3. ed. Petrópolis, RJ: Vozes. 
HOEFEL, Maria da Graça Luderitz \& JACQUES, Maria da Graça Corrêa (2006). "Síndrome do sobrevivente: um estudo comparativo entre trabalhadores de um banco privado e de um banco público". Boletim da Saúde, v. 20, n. 1, p. 107-17.

JACCOUD, Mylène \& MAYER, Robert (2010). "A observação direta e a pesquisa qualitativa”, em POUPART, Jean et al. (orgs.). A pesquisa qualitativa: enfoques epistemológicos e metodológicos. Petrópolis, RJ: Vozes. JACQUES, Maria da Graça Corrêa \& AMAZARRAY, Mayte Raya (2006). "Trabalho bancário e saúde mental no paradigma da excelência”. Boletim da Saúde, v. 20, n. 1, p. 93-105.

LAHIRE, Bernard (2005). "Patrimônios individuais de disposições, para uma sociologia à escala individual”. Sociologia, problemas e práticas, n. 49 , p. $11-42$.

LIMA, Jacob Carlos (2010). "Participação, empreendedorismo e autogestão: uma nova cultura do trabalho?”. Sociologias, v. 12, n. 25, p. 158-98.

(2012). Reestruturação bancária e precarização do trabalho nos anos 1990. João Pessoa: Editora UFPB.

MENDES, Ana Magnólia; COSTA, Viviane Paz \& BARROS, Paloma Castro da Rocha (2003). "Estratégias de enfrentamento do sofrimento psíquico no trabalho bancário”. Revista Estudos e Pesquisas em Psicologia, v. 3, n. 1, p. 38-48.

PALÁCIOS, Marisa; DUARTE, Francisco \& CÂMARA, Volney de Magalhães (2002). "Trabalho e sofrimento psíquico de caixas de agências bancárias na cidade do Rio de Janeiro". Cad. de Saúde Pública, v. 18, n. 3, p. 843-51. PETERS, Gabriel Moura (2006). Percursos na teoria das práticas sociais: Anthony Giddens e Pierre Bourdieu. Dissertação (mestrado) em sociologia. Brasília: UnB.

(2011). "A praxiologia culturalista de Anthony Giddens". Teoria e Pesquisa: Revista de Ciência Política, v. 20, n. 2, p. 123-47.

PFAFF, Nicole \& WELLER, Wivian (2010). Metodologias da pesquisa qualitativa em educação. Petrópolis, RJ: Vozes.

PIERSON, Françoise (2011). "Pour un apprentissage de la lutte et de la résistance des cadres pour limiter leur souffrance au travail: les apports de la théorie de la reconnaissance d'Axel Honneth”. M@n@gement, v. 5, n. 14, p. 352-70. Disponível em: <http://www.cairn.info/revue-management-2011-5-page-352.htm>. Acesso em: 28 abr. 2014.. 
REMY, Jean (2005). "Négociations et transaction sociale". Négociations, v. 1, n. 3, p. 81-95. Disponível em: <http://www.cairn.info/revue-negociations-2005-1-page-81.htm. Acesso em: 28 abr. 2014 ..

SANTOS, Marcelo Augusto Finazzi (2009). Patologia da solidão: o suicídio de bancários no contexto da nova organização do trabalho. Dissertação (mestrado) em administração. Brasília: UnB.

SARTORI, Giovanni (1994). A teoria da democracia revisitada. São Paulo: Ática.

SEGNINI, Liliana Rolfsen Petrilli (1999). "Reestruturação nos bancos no Brasil: desemprego, subcontratação e intensificação do trabalho". Educação \& Sociedade, v. 20, n. 67, p. 183-209.

SENNETT, Richard (2009). A corrosão do caráter: as conseqüências pessoais do trabalho no novo capitalismo. 14. ed. Rio de Janeiro: Record. (2012). A cultura do novo capitalismo. 4. ed. Rio de Janeiro: Record. SILVA, Luiz Sérgio; PINHEIRO, Tarcísio Márcio Magalhães \& SAKURAI, Emília (2007). "Reestruturação produtiva, impactos na saúde e sofrimento mental: o caso de um banco estatal em Minas Gerais, Brasil”. Cad. Saúde Pública, v. 23, n. 12, p. 2949-58.

SEEB-DF (2013). "Participe da pesquisa que vai mapear adoecimento na categoria”. 9. dez. Disponível em: <http://www.bancariosdf.com.br/ site/poupex/participe-da-pesquisa-que-vai-mapear-adoecimento-na-categoria >. Acesso em: 4 abr. 2013.

THIRY-CHERQUES, Hermano Roberto (2006). "Pierre Bourdieu: a teoria na prática”. Revista de Administração Pública, v. 40, n. 1, p. 27-55. THÉRET, Bruno (2003). "As instituições entre as estruturas e as ações". Lua Nova, n. 58, p. 225-54.

THOMPSON, Edward Paul (1981). A miséria da teoria ou um planetário de erros: uma crítica ao pensamento de Althusser. Rio de Janeiro: Zahar Editores.

\section{Resumo}

Os espaços de trabalho bancários são compreendidos como microcampos, com estruturas e disposições condicionando as práticas - transações sociais - de bancárias, bancários e clientes. Convivendo cotidianamente, esses agentes reconstituem transacionalmente escolhas e posturas adequadas a cada situação experienciada, participando de lutas políticas que redefinem continuamente as correlações de força, as hierarquias, as lideranças 
e os ordenamentos nos microcampos. São analisadas situações concretas no Banco do Brasil, a partir de dados gerados através de análise documental, entrevistas semiestruturadas e observação direta. Discutindo formas de exercício do poder e estratégias de luta e de resistência nos microcampos, os resultados revelam características, mudanças e complexidades sociopolíticas, sob os regimes de estabilidade e de empregabilidade no Banco do Brasil.

Palavras-chave: Lutas políticas; transações sociais; microcampos; bancários; estabilidade; empregabilidade.

\section{Abstract}

Bank workspaces are understood as micro fields, with structures and dispositions conditioning practices - social transactions - of employees and customers. Daily, these agents transactionally reconstitute appropriate choices and attitudes at every situation experienced by participating in political struggles that continually remake correlations of forces, hierarchies, leadership and power systems in micro fields. Concrete situations are analyzed at Bank of Brazil, based on data generated by document analysis, semi-structured interviews, and direct observation. By discussing forms of exercising power and strategies of struggle and resistance in micro fields, results reveal features, changes and socio-political complexities, under Bank of Brazil's Stability and Employability regimes. Keywords: Political struggles; social transactions; micro fields; bank; stability; employability.

Recebido em 30 de janeiro de 2015.

Aprovado em 12 de junho de 2015. 